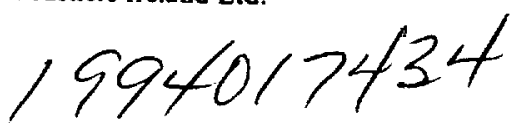

\title{
Effect of copper sulphate on the rate of afferent discharge in the gastric branch of the vagus nerve in the rat
}

\author{
Akira Niijima', Zheng-Yao Jiang', Nancy G. Daunton ${ }^{2}$ and Robert A. Fox ${ }^{3}$ \\ 'Depariment of Physiology. Niigata University School of Medicine. Niigata (Japan), 'Neuroscience Branch. \\ N.ASA Ames Research Center. Moffett Field. CA 94035 (U.S.A.) and 'Department of Psychology. San \\ Jose State University. San Jose. CA 94192 (U.S.A.)
}

(Received 20 May 1987; Accepted 26 May 1987)

Key words: Copper sulphate; Afferent discharge; Vagus nerve; Gastric branch; Gastric perfusion: Emesis

The afferent nerve activity was recorded from a nerve filament isolated from the peripheral cut end of the gastric branch of the vagus nerve. The gastric perfusion of $4 \mathrm{ml}$ of two different concentrations (0.04\% and $0.08 \%$ ) of $\mathrm{CuSO}_{4}$ solution provoked an increase in afferent activity. The stimulating effect of the $0.08 \%$ solution was stronger than that of the $0.04 \%$ solution, and lasted for a longer period of time. The observations suggest a possible mechanism by which $\mathrm{CuSO}_{4}$ elicits emesis.

It has been reported by Wang and Borrison [5] that the emetic action of copper sulphate $\left(\mathrm{CuSO}_{4}\right)$ is two-fold, involving a central as well as a peripheral effect. Their report indicated that the interruption of the vagi had a more profound effect on the threshold and latency of vomiting than did sympathectomy, which caused no discernible changes in these parameters. They stressed that the vagal afferents play an important role in the mediation of the peripheral effects of $\mathrm{CuSO}_{4}$. The present experiments were designed to follow up on these otservations by investigating the effect of $\mathrm{CuSO}_{4}$ on the rate of afferent discharge in the gastric branch of the vagus nerve.

Male Wistar rats weighing $300-400 \mathrm{~g}$ were used. Food, but not water, was removed $5 \mathrm{~h}$ before the experiment. Rats were anesthetized with $700 \mathrm{mg} / \mathrm{kg}$ of urethane and $50 \mathrm{mg} / \mathrm{kg}$ of chloralose, given i.p. A tracheal cannula was inserted.

The stomach could be perfused with $\mathrm{CuSO}_{4}$ or physiological saline through a catheter which was placed in the esophagus and directed toward the cardiac portion of the stomach. Another catether was placed in the pyloric portion of the stomach through the duodenum as an outlet for the perfusate. Before starting the experimen-

Correspondence: A. Niijima, Department of Physiology. Niigata University School of Medicine, Niigata 951. Japan.

0304-3940/87/5 03.50 C 1987 Elsevier Scientific Publishers Ireland Ltd. 
tal perfusions, the stomach was washed out with isotonic saline. Copper sulphate solutions of $0.04 \%$ and $0.08 \%$ and isotonic saline were used for the experimental perfusions. For each perfusion $4 \mathrm{ml}$ of solution at $38^{\circ} \mathrm{C}$ were injected by syringe into the stomach over a 1 -min period. The solution was kept in the stomach for $20 \mathrm{~min}$, after which time the stomach was flushed for I $\mathrm{min}$ with isotonic saline.

The afferent nerve activity was recorded from a nerve filament isolated from the peripheral cut end of the ventral or dorsal branch of the vagus nerve. The nerve filament was placed on a pair of silver wire electrodes and immersed in a mixture of liquid paraffin and vaseline. Nerve activity was amplified by means of a condensercoupled differential amplifier, and stored on magnetic tape. Analysis of nerve activity was performed after conversion of raw data to standard pulses by a window discriminator that distinguished the discharge of afferent fibers from background noise. To monitor the time course of changes in neural activity the rate of neural discharge was determined by a ratemeter with a reset time of 1 or $5 \mathrm{~s}$. The output of this ratemeter was displayed on a pen recorder. Normal animal body temperature was maintained by means of a heating pad. The ECG was monitored throughout the experiment.

The effect of $\mathrm{CuSO}_{4}$ on the afferent activity of the gastric branches of the vagus nerve was determined by comparing the mean number of spikes per second obtained over the 20 s (i.e. mean value of 20 successive measured samples) just before perfusion of $\mathrm{CuSO}_{4}$ (baseline, firing rate), with those obtained $20 \mathrm{~min}$ after the onset of perfusion, and $30 \mathrm{~min}$ after flushing out the perfusate with isotonic saline. Statistical significance of differences in discharge rate was determined by Student's $t$-test.

The perfusion of $4 \mathrm{ml}$ of two different concentrations $(0.04 \%$ and $0.08 \%)$ of $\mathrm{CuSO}_{4}$ solution provoked an increase in afferent activity of the gastric branch of the vagus nerve. After the onset of the perfusion with $\mathrm{CuSO}_{4}$ the activity increased gradually and the increase lasted until after the flushing of the gastric canal with isotonic saline. The stimulating effect of the $0.08 \%$ solution of $\mathrm{CuSO}_{4}$ was stronger than that of the $0.04 \%$ solution, and lasted for a longer period of time as shown in the upper trace of Fig. I. With the $0.08 \%$ solution the increase in vagal activity lasted in general for more than $1 \mathrm{~h}$, even though the stomach was flushed after 20 min of exposure to the $\mathrm{CuSO}_{4}$. The peak of activity provoked by the $\mathrm{CuSO}_{4}$ was reached after perfusate had been flushed out of the stomach (Fig. l, upper and lower trace).

The effects seen on neural activity were not caused by mechanical effect of the infusion of solution into the stomach, since the perfusion of $4 \mathrm{ml}$ of saline resulted in no noticeable increase in discharge rate beyond the transient increase that was observed at the onset of perfusion of both the $\mathrm{CuSO}_{4}$ solutions and the saline (Fig. 1 , lower (race).

Fig. 2 shows the mean discharge rate in spikes/s of 5 different preparations just before (control), $20 \mathrm{~min}$ after onset of $0.08 \% \mathrm{CuSO}_{4}$ perfusion, and $30 \mathrm{~min}$ after rinsing with saline. Those discharge rates are $6.4 \pm 0.3$ (S.E.M.), $13.4 \pm 1.8$ and $18.8 \pm 2.3$, respectively. The difference between firing rates obtained during the control period and the period 20 min after onset of perfusion, as well as between the control period and the period $30 \mathrm{~min}$ after rinsing were statistically significant (Fig. 2).

The experimental results indicate that gastric perfusion of $0.08 \% \mathrm{CuSO}_{4}$ solution 

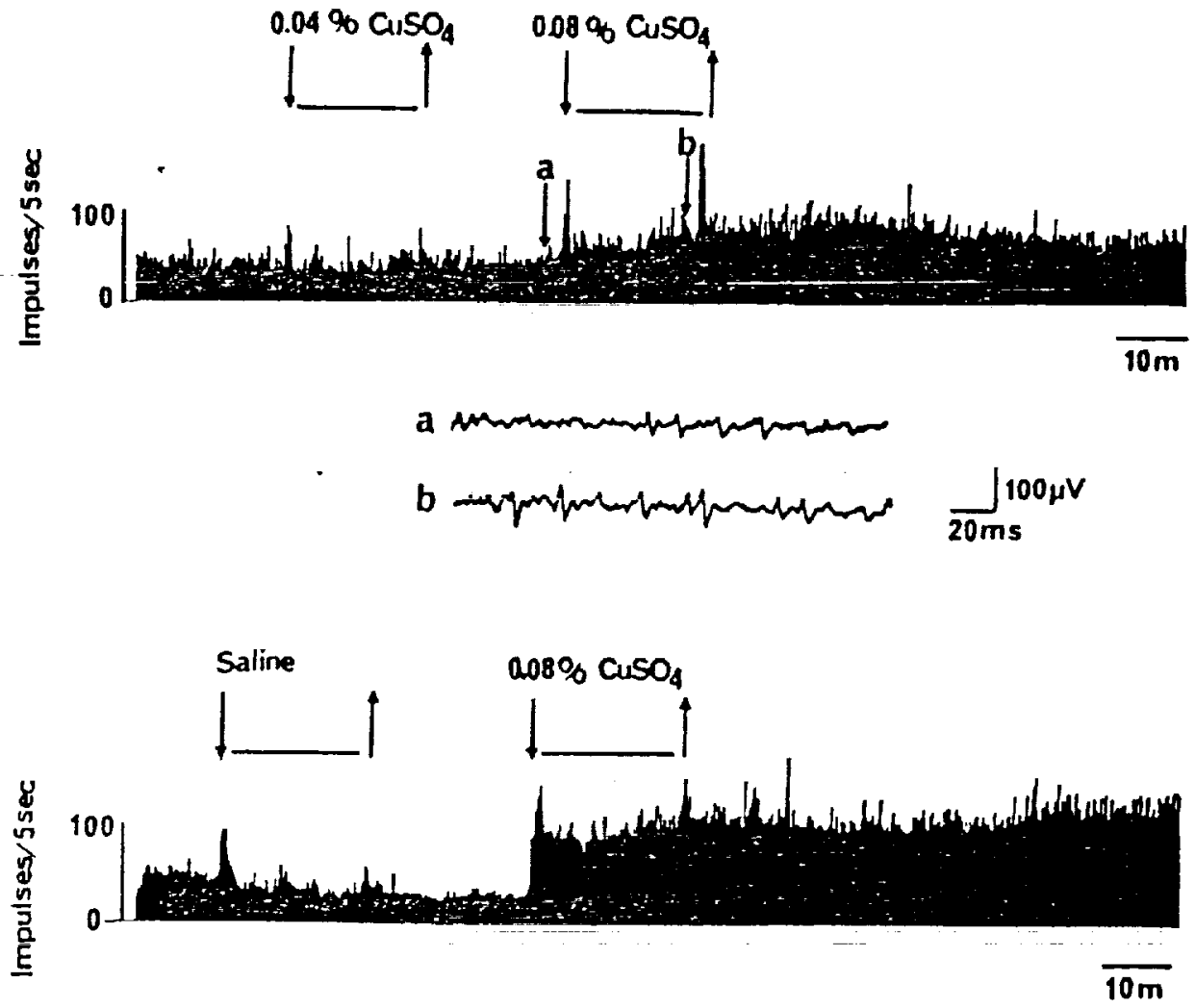

Fig. 1. Effect of gastric perfusion by $0.04 \%$ and $0.08 \% \mathrm{CuSO}_{4}$ solution and physiological saline on the afferent discharge rate of a vagal gastric nerve filament. Downward arrows show time of onset of perfusion. Upward arrows show the end of rinsing with saline. Horizontal bars indicate the duration of perfusion with $\mathrm{CuSO}_{4}$ solution and physiological saline. a: sample of nerve activity taken at time indicated by arrow $\cdot a$ '. before perfusion with $0.08 \% \mathrm{CuSO}_{4}$. b: sample of nerve activity obtained at time indicated by arrow 'b', during perfusion with $0.08 \%$ of CuSO,

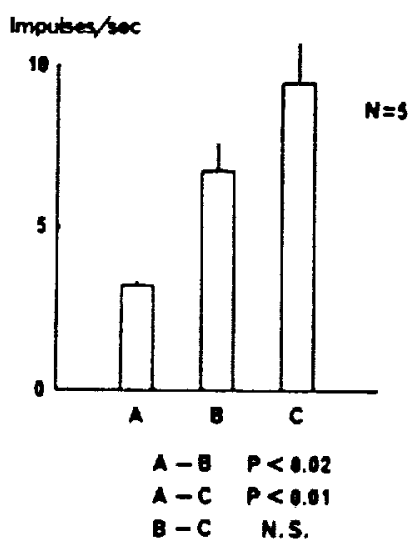

Fig. 2. Mean discharge rate of the gastric vagal afferents before (A), $20 \mathrm{~min}$ after onset (B) and $30 \mathrm{~min}$ after rinsing $(C)$ of perfusion by $0.08 \% \mathrm{CuSO}$, solution. 
increases afferent activity of the gastric branch of the vagus nerve. This finding suggests a possible physiological mechanism by which $\mathrm{CuSO}_{4}$ elicits emesis. The failure to induce emesis using $\mathrm{CuSO}_{4}$ after vagotomy (Oenchowski, quoted by Hatcher [1]) could thus be explained. The gradual increase in afferent discharge rate during $\mathrm{CuSO}_{4}$ perfusion also suggests a physiological mechanism to explain the latency to emesis (9-15 min) following oral administration of $\mathrm{CuSO}_{4}$.

It was established by Wang and Borrison [5] that the effective emetic concentration of $\mathrm{CuSO}_{4}$ for oral administration was $0.08 \%$ in the dog and cat. The observations in this paper on the effect of $\mathrm{CuSO}_{4}$ seem to be more consistent at the $0.08 \%$ than $0.04 \%$ concentration and might be expected to elicit vomiting more reliably at this concentration than at lower concentrations in the dog and cat.

The specific receptors mediating the gastric vagal afferent response to $\mathrm{CuSO}_{4}$ have not yet been identified, although several candidates exist. Mei [4] has demonstrated the existence of vagal chemoreceptors in the intestinal wall, while Iggo [2] has suggested that gastric $\mathrm{pH}$ receptors exist. Mei [3] has also reported the existence of receptors in the mucous membrane of the gastrointestinal wall. While any of these receptors might be stimulated by $\mathrm{CuSO}_{4}$ solutions, the exact source of the stimulating effect of $\mathrm{CuSO}_{4}$ on gastric vagal afferents is not known. The existence of a specific receptor for substances that act as emetics, such as $\mathrm{CuSO}_{4}$ and mustard, cannot be ruled out

Wang and Borrison [5] reported that vagotomy increases the latency for emesis induced by orally administered $\mathrm{CuSO}_{4}$. Their report mentioned that complete blockage of the emetic response to intragastric $\mathrm{CuSO}_{4}$ required vagotomy combined with sympathectomy. They further suggested that the gastric splanchnic afferent pathway may play a role in the emetic response. Further electrophysiological observations must be made to determine whether a splanchnic afferent pathway is involved in emesis induced by $\mathrm{CuSO}_{4}$ and/or other gastric irritants and to identify the receptors responsible for the effects of $\mathrm{CuSO}_{4}$.

1 Hatcher, R.A., The riechanism of vomiting, Physiol. Rev., 4 (1924) 497-504.

2 Iggo. A. Gastric mucosal chemoreceptors with vagal afferent fibers in the cal, Q. J. Exp. Physiol., 42 (1957) 398-409.

3 Mei. N., Mecanorecepleurs vagaux digestifs chez le chat, Exp. Brain Res., 11 (1970) 502-514.

4 Mei, N., Intestinal chemosensitivity. Physiol. Rev., 65 (1985) 211-237.

5 Wang. S.C. and Borrison, H.L., Copper sulphate emesis: a study of afferent pathways from the gastrointestinal tract. Am. J. Physiol., 1265 (1951) \$20-\$26. 